\title{
BMJ Open Caesarean section rates analysed using Robson's 10-Group Classification System: a cross-sectional study at a tertiary hospital in Ethiopia
}

\author{
Abdella Amano Abdo (D) ,' Sven Gudmund Hinderaker, ${ }^{2}$ \\ Achamyelesh Gebretsadik Tekle, ${ }^{3}$ Bernt Lindtjørn (1) ${ }^{2}$
}

To cite: Abdo AA,

Hinderaker SG, Tekle AG, et al. Caesarean section rates analysed using Robson's 10-Group Classification System: a cross-sectional study at a tertiary hospital in Ethiopia. BMJ Open 2020;10:e039098. doi:10.1136/ bmjopen-2020-039098

- Prepublication history and additional materials for this paper are available online. To view these files, please visit the journal online (http://dx.doi. org/10.1136/bmjopen-2020039098).

Received 08 April 2020 Revised 07 October 2020 Accepted 08 0ctober 2020

D) Check for updates

(c) Author(s) (or their employer(s)) 2020. Re-use permitted under CC BY-NC. No commercial re-use. See rights and permissions. Published by BMJ.

${ }^{1}$ Epidemiology, Hawassa University College of Medicine and Health Sciences, Hawassa, Ethiopia

${ }^{2}$ Center for International Health, University of Bergen, Bergen,

Norway

${ }^{3}$ Public Health, Hawassa University College of Medicine and Health Sciences, Hawassa, Ethiopia

Correspondence to Abdella Amano Abdo; a2ay.oro@gmail.com

\section{ABSTRACT}

Objective The aim of this study was to assess the caesarean section (CS) rates using Robson's 10-Group Classification System among women who gave birth at Hawassa University Referral Hospital in southern Ethiopia. Design Cross-sectional study design to determine CS rate using Robson's 10-Group Classification System.

Setting Hawassa University Referral Hospital in south Ethiopia.

Participants 4004 women who gave birth in Hawassa University Referral Hospital from June 2018 to June 2019. Results The 4004 women gave birth to 4165 babies. The overall CS rate was $32.8 \%$ (95\% Cl: $31.4 \%-34.3 \%)$. The major contributors to the overall CS rates were: Robson group 1 (nulliparous women with singleton pregnancy at term in spontaneous labour) 22.9\%; group 5 (multiparous women with at least one previous CS) $21.4 \%$ and group 3 (multiparous women without previous CS, with singleton pregnancy in spontaneous labour) $17.3 \%$. The most commonly reported indications for CS were 'fetal compromise' (35.3\%) followed by previous CS (20.3\%) and obstructed labour (10.7\%).

Conclusion A high proportion of women giving birth at this hospital were given a CS, and many of them were in a low-risk group. Few had trial of labour. More active use of partogram, improving fetal heartbeat-monitoring system, implementing midwife-led care, involving a companion during labour and auditing the appropriateness of CS indications may help to reduce the CS rate.

\section{INTRODUCTION}

Caesarean section (CS) is a life-saving intervention for both the woman and newborn if a complication occurs during late pregnancy and childbirth. It is the most common surgical intervention in many countries. ${ }^{1}$ The proportion of women giving birth by $\mathrm{CS}$ is used by the WHO as an indicator of the provision of life-saving services for both mothers and newborns. ${ }^{2} \mathrm{WHO}$ suggests that in normal populations CS rates should not exceed $10 \%-15 \% .^{3}$ However, there is a growing concern about the increasing percentage of CS globally.The CS rates above $15 \%$ are
Strengths and limitations of this study

- It was the first study in Ethiopia that assesses the caesarean section rate using Robson's 10-Group Classification System for all labouring mothers in a hospital.

- The study used prospective birth registration, hence the risk of incomplete data minimised.

- All women who gave birth in study hospital were included, reducing the risk for selection bias.

- Since the study was conducted in single hospital with high referral and most complicated cases, the finding might be less generalisable.

- The study used birth weight for gestational age determination for some mothers and the possibility of misclassification among the Robson group cannot be ruled out.

not associated with improved maternal and neonatal health, ${ }^{4}$ and reasons for a CS may be other than medical; in some countries, for example, it may be a cost-free option for expecting mothers. ${ }^{56}$

CS performed for women who do not need it can have negative consequences for the mothers as well as their babies, especially when the procedure is done in the absence of adequate facilities, skills and comprehensive care. ${ }^{7}$ Though CS is effective in reducing maternal and neonatal mortality and morbidity, the procedure is also associated with increased maternal risk of infection, bleeding, blood transfusion, hysterectomy and death compared with normal delivery. ${ }^{8}$ Indeed, even small operations carry some risks and must be compared with the risks of not undertaking the procedure. A woman who undergoes a CS will have a slightly increased risk for her subsequent babies to have fetal distress, preterm birth and stillbirth. ${ }^{9-11}$

In 2016, globally, the population-based CS rate varied from $6 \%$ to $27.2 \%,{ }^{12}$ and the 
global rate of CS births had doubled over the last 15 years. ${ }^{13}$ In Ethiopia, the national population-based CS rate had been the lowest in the world, ${ }^{12} 14$ but a national review conducted in 2011 covering 797 facilities indicated a CS rate of $15 \%$ in public facilities and $46.1 \%$ in privately owned facilities. ${ }^{15}$ The CS rate at a university hospital in eastern Ethiopia was 25.7\%. ${ }^{16}$ Many of these facility-based CS rates represent a selected population of women, and hence not necessarily representing the CS rate in the population.

Though there is no consensus in defining the optimal CS rate at any level due to lack of reliable and internationally accepted classification system, the 10-Group Classification System created by Robson has now been accepted and used in many countries. ${ }^{17} 18$ This system helps institution-specific monitoring and auditing and offers a standardised comparison method for use between institutions, countries and time points. ${ }^{19}$

WHO has been recommending using this system to assess, monitor and compare CS rates since $2015,{ }^{2}$ but it is not yet implemented in Ethiopia. A study on CS was conducted using Robson's classification system at a university hospital in eastern Ethiopia ${ }^{16}$ but was limited to women who underwent CS, and was not done according to the Robson implementation manual. ${ }^{20}$ Therefore, the aim of our study was to determine CS rate using 10-Group Classification System among all the women who gave birth at Hawassa University Referral Hospital in southern Ethiopia in 2018-2019.

\section{MATERIALS AND METHODS Study setting}

The study was conducted at Hawassa University Referral Hospital, which is $275 \mathrm{~km}$ to the south of Addis Ababa, the capital city of Ethiopia. The hospital provides healthcare services as both primary healthcare for Hawassa city and its nearby districts, and as tertiary care services for the region Southern Nation Nationalities and Peoples, including some neighbouring regions. Although it provides tertiary care for a population of 15 million, over $90 \%$ of the mothers came from two towns (Shashamanne and Hawassa). According to 2019 Ethiopian Mini Demographic and Health Survey report, 69.4\%, 47.6\% and $32 \%$ of the women had at least one antenatal care (ANC) follow-up, health facility delivery and postnatal care follow-up, respectively, in Southern Nation Nationalities and Peoples region. ${ }^{21}$ All pregnant women are encouraged to have a minimum of four ANC visits and to deliver at health facilities. Preventive services such as screening for HIV/AIDS, syphilis, tetanus toxoid vaccination and iron folate supplementation are routinely given for pregnant mothers during their ANC follow-up. All services related to delivery, including CS are expected to be given free of charge for delivering mothers at the hospital. But sometimes the women are requested to buy drugs, intravenous fluids or gloves, when unavailable in the hospital dispensary. No payment (in addition to ordinary salary) is given to the obstetrician for performing CS. Hawassa University Referral Hospital is providing both basic and comprehensive management of maternal, newborn and child health services for more than 4500 births annually. The hospital is also serving as teaching hospital for health science and medical students including residency programmes. The Department of Obstetrics and Gynaecology had 6 obstetricians and gynaecologists, 80 midwives, as well as its own operation theatre for obstetrics cases. According to national guidelines for staffing, the recommended number of obstetrician for specialised hospital is 13 and the number at this hospital is less than recommended. ${ }^{22}$

\section{Study design and participants}

The design was cross-sectional and included all women who gave birth at the hospital between June 2018 and June 2019. A medical birth registry was adapted from the Kilimanjaro Christian Medical Centre in Tanzania ${ }^{23}$ and used to collect the data.

\section{Variables}

The main outcome variable was the rate of CS, in all deliveries. Other variables were as follows: sociodemographic characteristics (maternal age, residence, educational status, occupational status), maternal characteristics (history of CS and parity) and pregnancy-related information (gestational age, fetal presentation, number of fetuses and onset of labour). For those women who underwent CS, information about the indications of CS was also collected.

The CS rates were categorised by the Robson classification system shown in table $1^{20}$ using six obstetric parameters: (1) Fetal lie and presentations were classified as cephalic, breech or transverse/oblique. (2) Gestational age was categorised as a term ( $\geq 37$ weeks) or preterm ( $<37$ weeks). Gestational age assessment should ideally be done by early ultrasound. But in our study, since most of the women did not have early ultrasound measurement, we used the date of last menstrual period and third trimester ultrasound to assess gestational age. In the case of no third trimester ultrasound or unknown last menstrual period, a combination of physical examination and estimated fetal weight were used for estimation of gestational age. For cases with undocumented gestational age, we used a birth weight of $\geq 2500$ grams as a proxy to term pregnancy. (3) The onset of labour was categorised as spontaneous, induced or CS before labour. (4) Parity was classified as nulliparous or multiparous. (5) The number of fetuses was categorised as singleton or multiples. (6) History of previous CS was categorised as one, and two or more.

Fetal compromise was defined as a fetus having one of the following conditions: fetal distress, cord prolapse or intrauterine growth restriction. The hospital has one cardiotocography that was not used. Ultrasound was occasionally used, but in most of the cases the fetal heartbeat was monitored using fetoscope. We categorised the 


\begin{tabular}{|c|c|}
\hline Group & Description \\
\hline 1 & $\begin{array}{l}\text { Nulliparous, singleton, cephalic, } \geq 37 \text { weeks' } \\
\text { gestation, in spontaneous labour }\end{array}$ \\
\hline 2 & $\begin{array}{l}\text { Nulliparous, singleton, cephalic, } \geq 37 \text { weeks' } \\
\text { gestation, induced labour or CS before labour }\end{array}$ \\
\hline $2 a$ & Labour induced \\
\hline $2 b$ & Pre-labour CS \\
\hline 3 & $\begin{array}{l}\text { Multiparous (excluding previous CS), singleton, } \\
\text { cephalic, } \geq 37 \text { weeks' gestation, in spontaneous } \\
\text { labour }\end{array}$ \\
\hline 4 & $\begin{array}{l}\text { Multiparous without a previous CS, with singleton, } \\
\text { cephalic pregnancy, } \geq 37 \text { weeks' gestation, induced } \\
\text { or CS before labour }\end{array}$ \\
\hline $4 a$ & Labour induced \\
\hline $4 b$ & Pre-labour CS \\
\hline 5 & $\begin{array}{l}\text { Previous CS, singleton, cephalic, } \geq 37 \text { weeks' } \\
\text { gestation }\end{array}$ \\
\hline 5.1 & With one previous CS \\
\hline 5.2 & With two or more previous CSs \\
\hline 6 & All nulliparous with a single breech \\
\hline 7 & $\begin{array}{l}\text { All multiparous with a single breech (including } \\
\text { previous CS) }\end{array}$ \\
\hline 8 & All multiple pregnancies (including previous CS) \\
\hline 9 & $\begin{array}{l}\text { All women with a single pregnancy in a transverse } \\
\text { or oblique lie (including those with previous CS) }\end{array}$ \\
\hline 10 & $\begin{array}{l}\text { All singleton, cephalic, }<37 \text { weeks' gestation } \\
\text { pregnancies (including CS) }\end{array}$ \\
\hline
\end{tabular}

Source: WHO (2017). ${ }^{20}$

CS, caesarean section.

need for CS as 'Absolute indication' and 'Not absolute indication, ${ }^{24}$

\section{Data collection}

Data were recorded by three midwives in the maternity ward. Data collectors and supervisors were trained and supervised by the principal investigator. Information about the sociodemographic characteristics of delivering mothers was collected through interviews at the time of admission if the women were stable or before discharge from the hospital. Information about CS was retrieved from the operation theatre register and double-checked with the midwives' delivery logbook and the admission and discharge registers. Completeness of data was checked by the principal investigator.

\section{Data processing and analysis}

All registered data were double entered using EpiData V.3.1 (EpiData Association, Odense, Denmark) and consistency was checked and any necessary corrections were made before data analysis. Data were analysed using SPSS V.25.
Descriptive statistics with frequencies and percentages for categorical data, as well as means and SD for numerical data were used to summarise the data. The WHO Robson implementation manual was used to interpret the results of this study..$^{20}$ For determining CS rate, we used those mothers with complete data on Robson's group parameters. Those mothers with missing data were excluded from analysis.

\section{Patient and public involvement}

Patients or public were not involved in the design, or conduct, or reporting, or dissemination plan of our research.

\section{RESULTS}

In the 12-month study period, there were 4031 women coming to give birth at Hawassa University Referral Hospital. Of these clients, 27 had incomplete records and were excluded, resulting in 4004 women giving birth to 4165 babies for analysis. The mean age of the women was 26 years. It ranged from 13 to 45 years. Their sociodemographic characteristics are shown in table 2 . We notice that many were urban dwellers and housewives, and most had some basic formal education.

The obstetric characteristics of the study participants and the outcomes of the women who gave birth are given in table 3. Two out of five $(41.1 \%)$ of the study participants were nulliparous. Almost all of the study participants had had at least one ANC visit during this pregnancy. Of all births, $15.1 \%$ were preterm. CS was performed on 1314 $(32.8 \%)$ women, 165 (12.6\%) of them planned. The perinatal mortality was 75 perinatal death/1000 live births was based on deaths occurring in the hospital.

\section{Robson's 10-Group Classification System}

Table 4 shows the women who gave birth according to Robson classification. We notice that the groups most represented by type of obstetrics population (group size) were: multiparous women without previous CS; women with a singleton pregnancy in spontaneous labour (group $3)$; nulliparous women with singleton pregnancy in spontaneous labour (group 1) and women with preterm birth (group 10).

The overall CS rate in this study was $32.8 \%$ (95\% CI: $31.4 \%-34.3 \%)$. The major contributors to the overall CS rate were: group 1 (nulliparous women with singleton pregnancy in spontaneous labour), group 5 (multiparous women with at least one previous CS) and group 3 (multiparous women without previous CS, with singleton pregnancy in spontaneous labour) (table 4).

From an obstetrician's perspective, the most common indications for CS were fetal compromise, obstructed labour and previous CS (figure 1: indications for performing CS among women who gave birth at Hawassa University Referral Hospital, Ethiopia, 2018-2019). In this study, 227/1314 (17.3\%) CS were performed for absolute maternal indications. For non-absolute indications, CS 
Table 2 Sociodemographic characteristics of women who gave birth at Hawassa University Referral Hospital, Ethiopia, 2018-2019

\begin{tabular}{|c|c|c|c|}
\hline \multicolumn{2}{|l|}{ Variables } & \multirow{2}{*}{$\frac{\text { Number }}{4004}$} & \multirow{2}{*}{$\begin{array}{l}\text { Percent (\%) } \\
100\end{array}$} \\
\hline Total & & & \\
\hline \multirow{4}{*}{$\begin{array}{l}\text { Maternal age } \\
\text { (years) }\end{array}$} & $<20$ & 187 & 4.7 \\
\hline & $20-34$ & 3467 & 86.6 \\
\hline & 35 and above & 347 & 8.7 \\
\hline & Not recorded & 2 & 0.1 \\
\hline \multirow[t]{3}{*}{ Residence } & Urban & 3669 & 91.6 \\
\hline & Rural & 318 & 7.9 \\
\hline & Not recorded & 17 & 0.4 \\
\hline \multirow[t]{5}{*}{$\begin{array}{l}\text { Educational } \\
\text { level }\end{array}$} & $\begin{array}{l}\text { Cannot read and } \\
\text { write }\end{array}$ & 283 & 7.1 \\
\hline & Primary (1-8) & 1741 & 43.5 \\
\hline & Secondary (9-12) & 1233 & 30.8 \\
\hline & College and above & 715 & 17.9 \\
\hline & Not recorded & 32 & 0.8 \\
\hline \multirow{5}{*}{$\begin{array}{l}\text { Occupational } \\
\text { status }\end{array}$} & Housewife & 2834 & 70.8 \\
\hline & Merchant & 307 & 7.7 \\
\hline & Employer & 624 & 15.6 \\
\hline & Others* & 167 & 4.2 \\
\hline & Not recorded & 72 & 1.8 \\
\hline \multirow[t]{4}{*}{ Marital status } & Married & 3949 & 98.6 \\
\hline & Single & 29 & 0.7 \\
\hline & Divorced/widowed & 9 & 0.2 \\
\hline & Not recorded & 17 & 0.4 \\
\hline \multirow{2}{*}{$\begin{array}{l}\text { Referred to } \\
\text { give birth }\end{array}$} & Yes & 1468 & 36.7 \\
\hline & No & 2536 & 63.3 \\
\hline
\end{tabular}

*Daily labourer, student, farmer.

was performed in 968/1314 (73.7\%) of cases, mainly nonreassuring fetal heartbeat pattern (fetal distress). The remaining $9.0 \%$ of CS could not be classified in this way, and included post-term pregnancy, premature rupture of membrane, multiple pregnancies and polyhydramnios/ oligohydramnios.

\section{DISCUSSION}

A high proportion of women who gave birth in Hawassa University Referral Hospital were through CS, almost one-third. The major contributors to the overall CS rate were group 1 (nulliparous with singleton pregnancy in spontaneous labour), group 5 (multiparous women with at least one previous CS) and group 3 (multiparous women without previous $\mathrm{CS}$, with singleton pregnancy in spontaneous labour). The most commonly reported indications for CS were a fetal compromise, previous CS and obstructed labour.
Table 3 Obstetrics characteristics of women who gave birth and their outcomes at Hawassa University Referral Hospital, Ethiopia, 2018-2019

\begin{tabular}{|c|c|c|c|}
\hline Variables & & Number & Percent (\%) \\
\hline \multirow{3}{*}{$\begin{array}{l}\text { Age at first } \\
\text { marriage }\end{array}$} & 18 years or less & 1091 & 27.2 \\
\hline & Above 18 years & 2861 & 71.5 \\
\hline & Not recorded & 52 & 1.3 \\
\hline \multirow{3}{*}{$\begin{array}{l}\text { Age at first } \\
\text { pregnancy }\end{array}$} & 18 years or less & 748 & 18.7 \\
\hline & Above 18 years & 3205 & 80 \\
\hline & Not recorded & 50 & 1.3 \\
\hline \multirow[t]{3}{*}{ Parity } & 0 & 1646 & 41.1 \\
\hline & $1-4$ & 2185 & 54.6 \\
\hline & $>4$ & 173 & 4.3 \\
\hline \multirow{3}{*}{$\begin{array}{l}\text { ANC this } \\
\text { pregnancy }\end{array}$} & Yes & 3931 & 98.2 \\
\hline & No & 57 & 1.4 \\
\hline & Not recorded & 16 & 0.4 \\
\hline \multirow{3}{*}{$\begin{array}{l}\text { Gestational } \\
\text { age }\end{array}$} & Preterm (<37 weeks) & 606 & 15.1 \\
\hline & Term (37-42 weeks) & 3253 & 81.2 \\
\hline & $\begin{array}{l}\text { Post-term (>42 } \\
\text { weeks) }\end{array}$ & 145 & 3.6 \\
\hline \multirow{3}{*}{$\begin{array}{l}\text { Onset of } \\
\text { labour }\end{array}$} & Induced & 398 & 9.9 \\
\hline & Spontaneous & 3441 & 85.9 \\
\hline & Pre-labour CS & 165 & 4.2 \\
\hline \multirow{3}{*}{$\begin{array}{l}\text { Fetal lie and } \\
\text { presentation }\end{array}$} & Cephalic & 3844 & 96 \\
\hline & Breech & 143 & 3.6 \\
\hline & Transverse/oblique & 17 & 0.4 \\
\hline \multirow[t]{5}{*}{$\begin{array}{l}\text { Mode of } \\
\text { delivery }\end{array}$} & $\begin{array}{l}\text { Spontaneous vaginal } \\
\text { delivery }\end{array}$ & 2605 & 65.1 \\
\hline & Instrumental delivery & 85 & 2.1 \\
\hline & CS & 1314 & 32.8 \\
\hline & CS emergency & 1149 & 87.4 \\
\hline & CS planned & 165 & 12.6 \\
\hline \multirow{2}{*}{$\begin{array}{l}\text { Number of } \\
\text { fetus at birth } \\
(n=4165)\end{array}$} & Singleton & 3850 & 92.4 \\
\hline & Multiple & 315 & 7.6 \\
\hline \multirow{3}{*}{$\begin{array}{l}\text { Type of } \\
\text { multiple } \\
\text { births }(n=315)\end{array}$} & Twin & 292 & 92.7 \\
\hline & Triplets & 19 & 6 \\
\hline & Quadruplets & 4 & 1.3 \\
\hline \multirow{4}{*}{$\begin{array}{l}\text { Birth weight } \\
\text { (in grams) } \\
\text { ( } n=4165)\end{array}$} & $<2500$ & 592 & 14.2 \\
\hline & $2500-4000$ & 3355 & 80.6 \\
\hline & $>4000$ & 188 & 4.5 \\
\hline & Not recorded & 30 & 0.7 \\
\hline \multirow{2}{*}{$\begin{array}{l}\text { Previous CS } \\
(n=2358)\end{array}$} & Yes & 438 & 18.6 \\
\hline & No & 1920 & 81.4 \\
\hline
\end{tabular}

Instrumental delivery includes vacuum and forceps delivery. ANC, antenatal care; CS, caesarean section.

In this study we interpreted the findings based on Robson's implementation manual ${ }^{20}$ : thus, we assessed the quality of the data, the population attending the services (shown in online supplemental appendix 1), and we 
Table 4 Robson's classification system among women who gave birth at Hawassa University Referral Hospital, Hawassa, south Ethiopia, 2018-2019

\begin{tabular}{|c|c|c|c|c|c|c|}
\hline Robson group & $\begin{array}{l}\text { CS in } \\
\text { group }\end{array}$ & $\begin{array}{l}\text { Number } \\
\text { in group }\end{array}$ & $\begin{array}{l}\text { Group } \\
\text { size (\%) }\end{array}$ & $\begin{array}{l}\text { CS in } \\
\text { group } \\
(\%)\end{array}$ & $\begin{array}{l}\text { Absolute group } \\
\text { contribution to } \\
\text { overall CS rate (\%) }\end{array}$ & $\begin{array}{l}\text { Relative } \\
\text { contribution of the } \\
\text { group to the overall } \\
\text { CS rate (\%) }\end{array}$ \\
\hline $\begin{array}{l}\text { Group } 2 \text { (nulliparous women with singleton } \\
\text { pregnancy who had induced labour or pre- } \\
\text { labour CS) }\end{array}$ & 97 & 227 & 5.7 & 42.7 & 2.4 & 7.4 \\
\hline Group 2a (induced labour) & 55 & 185 & 4.6 & 29.7 & 1.4 & 4.2 \\
\hline Group 2b (pre-labour CS) & 42 & 42 & 1.1 & 100 & 1 & 3.2 \\
\hline $\begin{array}{l}\text { Group } 3 \text { (multiparous women without previous } \\
\text { CS, with singleton pregnancy in spontaneous } \\
\text { labour) }\end{array}$ & 227 & 1356 & 33.9 & 16.7 & 5.7 & 17.3 \\
\hline Group 4b (pre-labour CS) & 35 & 35 & 0.8 & 100 & 0.9 & 2.7 \\
\hline $\begin{array}{l}\text { Group } 5 \text { (multiparous women with at least one } \\
\text { previous CS) }\end{array}$ & 281 & 362 & 9 & 77.6 & 7 & 21.4 \\
\hline Group 5.1 (one previous CS) & 214 & 290 & 7.2 & 73.8 & 5.3 & 16.3 \\
\hline Group 5.2 (two or more previous CS) & 57 & 72 & 1.8 & 79.2 & 1.4 & 4.3 \\
\hline $\begin{array}{l}\text { Group } 6 \text { (nulliparous women with singleton } \\
\text { breech) }\end{array}$ & 38 & 46 & 1.2 & 82.6 & 0.9 & 2.9 \\
\hline $\begin{array}{l}\text { Group } 7 \text { (multiparous women with singleton } \\
\text { breech) }\end{array}$ & 58 & 65 & 1.6 & 89.2 & 1.4 & 4.4 \\
\hline Group 8 (all multiple pregnancies) & 91 & 154 & 3.9 & 59.1 & 2.3 & 6.9 \\
\hline
\end{tabular}

Group size $(\%)=n$ of women in the group/total number of women who gave birth in the hospital $\times 100$.

Group CS rate $(\%)=n$ of CS in the group/total number of women in the group $\times 100$.

Absolute contribution $(\%)=n$ of CS in the group/total number of women who gave birth in the hospital $\times 100$.

Relative contribution $(\%)=n$ of CS in the group/total number of CS in the hospital $\times 100$.

CS, caesarean section.

analysed the proportion of CS in each group (shown in online supplemental appendix 2).

Our study had several strengths. To our knowledge, this study is the first study at a major hospital in Ethiopia that assessed the CS rate using Robson's 10-Group Classification System for all labouring mothers. The birth registration was prospective and consecutive; hence the risk of incomplete data was minimised. All women who gave birth in the hospital during the study were included and this may have reduced selection bias.

The study also had some weaknesses. The study was conducted in a single hospital, and since it is a referral hospital, the selection of participants may be biased to some degree, and for this reason the findings might be less generalisable. However, standardisation according to Robson is able to be used in such situations. Its use permits valid and useful comparisons to be done even at different levels of care. Another weakness is that the study used birth weight to determine gestational age for some mothers, and this could lead to a misclassification of some births into a wrong Robson group. We assessed whether this results in misclassification among Robson group according to WHO Robson implementation manual and the risk of misclassification was minimal. A third potential weakness involved inconsistent use of partogram and fetal heartbeat. This makes the criteria for decisions and indications for CS unclear and left much up to individual doctor's discretion.

The manual for interpretation of CS rates stated that the size of group 9 (women with transverse lie, singletons pregnancy), should be less than $1 \%$ of the total and the CS rate should be $100 \%$ for this group. ${ }^{20}$ In our study, the size of group 9 was $0.4 \%$ and the CS rate in this group was $100 \%$, suggesting minimal misclassification in 


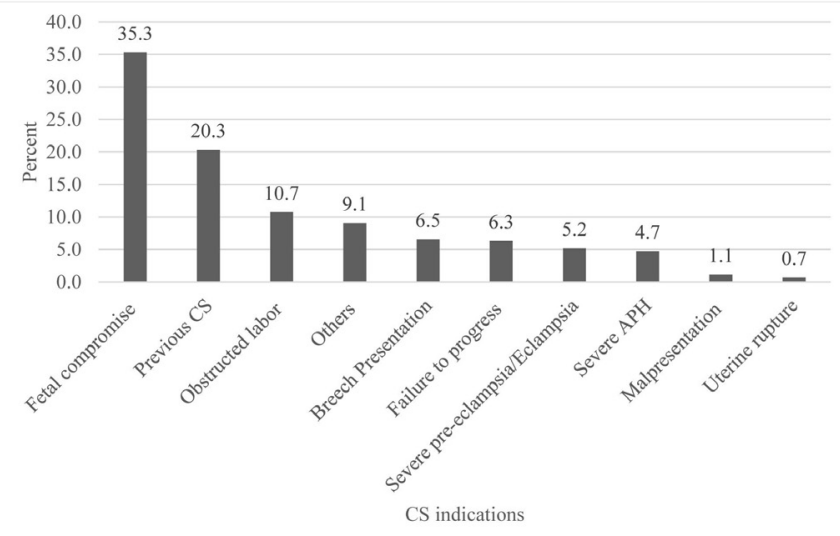

Figure 1 Indications for performing caesarean section (CS) among women who gave birth at Hawassa University Referral Hospital, Ethiopia, 2018-2019. Failure to progress means prolonged labour, cervical arrest and failed induction; fetal compromise means fetal distress, cord prolapse and intrauterine growth restriction; obstructed labour means cephalopelvic disproportion, macrosomia and unspecified disproportions; malpresentation means transverse, oblique or brow; others include post-term pregnancy, premature rupture of membrane, multiple pregnancies and polyhydramnios/ oligohydramnios. APH, antepartum haemorrhage.

this group, and the size of group 9 was similar to other studies. $^{202526}$

In our study several indicators were in line with the comparison populations given in Robson's manual; the proportion of women with breech pregnancy (groups 6 and 7), the ratio of the size of group 1 (nulliparous women with singleton pregnancy in spontaneous labour) and group 2 (nulliparous women with singleton pregnancy, who had induced labour or pre-labour CS), as well as the ratio of the size of group 3 (multiparous women without previous CS, with singleton pregnancy in spontaneous labour) and group 4 (multiparous women without previous $C S$, with singleton pregnancy, who had induced labour or pre-labour CS) ${ }^{20}{ }^{2526}$ However, the proportion of group 1 (nulliparous women with singleton pregnancy in spontaneous labour) and group 2 (nulliparous women with singleton pregnancy, who had induced labour or pre-labour CS) was slightly lower than the comparison populations. ${ }^{202526}$ This may be due to the low proportions of nulliparous women in our study. The proportion of group 3 (multiparous women without previous CS, with singleton pregnancy in spontaneous labour) and group 4 (multiparous women without previous CS, with singleton pregnancy, who had induced labour or prelabour CS) was higher than the Robson reference population. ${ }^{20}$ This may be explained by the fact that we had a high proportion of multiparous women in our study populations. According to Robson, the proportion of group 5 (multiparous women with at least one previous CS) should, be about half of all the CS. In our study, the proportion of group 5 represents less than $10 \%$ of the total women delivered in the hospital, which may reflect a low CS rate in previous years. The proportion of group
8 (women with multiple pregnancies) and group 10 (women with preterm pregnancy) in our study was similar with the comparison population. ${ }^{2025} 26$

The CS rate in Robson group 1 (nulliparous women with singleton pregnancy in spontaneous labour) was $27.5 \%$, which is much higher than Robson's examples showing that rates under $10 \%$ are achievable. ${ }^{20}$ This may reflect a selection among nullipara, where many normal spontaneous deliveries take place at lower health facilities (health centres and primary hospitals), and those who attend this referral hospital are selected, either referred or they decided themselves for unknown reasons to attend the hospital. Alternatively, it may reflect a low 'threshold' interpreting criterion for a CS.

The CS rate in group 2 (nulliparous women with singleton pregnancy, who had labour induced or prelabour CS) was similar to the comparison populations, ${ }^{25} 26$ but higher than Robson's guideline (CS rate between 20 and 35). ${ }^{20}$ This may reflect that the threshold for deciding on doing CS is too low, and this may happen at extremely busy labour wards; for example, the ward is so busy that calling a doctor and suggesting a CS in a case of slow progress may be preferred to a time-consuming trial of labour. This 'low' CS threshold may explain why group 3 (multiparous women without previous CS, with singleton pregnancy in spontaneous labour) also had a higher CS rate $(17 \%)$ than the comparisons $(3 \%-5 \%) .{ }^{2025} 26$ It could also be partly due to some misclassification by including women from group 5 (multiparous women with at least one previous CS) in group 3, but this is less likely.

Robson guideline stated that the CS rate in group 4 (multiparous women without a previous CS, with singleton pregnancy, who had induced labour or prelabour CS) is rarely should be higher than $15 \%$, while in our study this rate was much higher $(43 \%)$. This may be because of the high CS rate in women who underwent induction of labour (group 4a) $(26.8 \%)$, which contributed to the high overall CS rate in group 4. Also, it may partly be due to a high proportion of failed inductions, or possible misclassifications by including group 5 (multiparous women with at least one previous CS) in group 4 .

The CS rate in group 5 (multiparous women with at least one previous CS) in our study was $77.6 \%$, which is higher than the Robson guideline $(50 \%-60 \%) .{ }^{20}$ This indicates that in our study, too few women were offered a trial of labour after having had previous CS.

The CS rate for breech in group 6 (nulliparous women with singleton breech pregnancy) and group 7 (multiparous women with a singleton breech pregnancy including previous CS) in our study was similar to comparison populations. ${ }^{20} 2526$

The examples given by Robson in his guideline stated that nullipara and women with a previous CS contribute to $66 \%$ of CS at the hospital, comprising group 1 (nulliparous women with singleton pregnancy in spontaneous labour), group 2 (nulliparous women with singleton pregnancy, who had induced labour or pre-labour CS) and group 5 (multiparous women with at least one 
previous CS). ${ }^{20}$ In our study, the relative contribution of these three groups (group 1, 2 and 5) to the overall $\mathrm{CS}$ rate was $51.7 \%$. This difference may be that the study area had few nullipara with planned CS, as seen in the low relative contribution of group 2 (nulliparous women with singleton pregnancy, who had induced labour or pre-labour CS) to the overall CS rate which in our study was $(7.38 \%)$.

The overall CS rate in our hospital $(32.8 \%)$ is higher than the WHO recommendation 10\%-15\%. ${ }^{3}$ The high CS rate in our study may be due to several issues. One factor could be that Hawassa University Referral Hospital as a teaching hospital has doctors under specialist training performing CS without following strict indications for performing CS. In our study hospital, there is no oneto-one midwifery-led care, and this may also be a possible reason for the high CS rate in our study. Several studies have shown midwifery-led care to significantly reduce CS rate. ${ }^{27-31}$ In addition, there was no support of companion during labour in our hospital, and several studies showed that support from a companion during labour and childbirth reduced CS rate and improved maternal and newborn birth outcomes. ${ }^{32-34}$ Another possible driving factors for this high CS rate could be the hospital is a referral hospital where more than one-third of women referred to this hospital with different emergency situations that may need emergency management through CS delivery. ${ }^{35}$ Nearly three-quarters $(73.7 \%)$ of CS in this study was performed for non-absolute maternal indications, mainly fetal distress, and CS may be performed for some women without clear appropriate indications. Fetal monitoring was not optimal, and this may have contributed to the high prevalence of 'fetal distress'. Also, a large proportion were urban women $(91.6 \%)$ who gave birth in the hospital, and urban women are shown to have higher $\mathrm{CS}$ rates than the rural women in other settings also. ${ }^{36-38}$

Our study showed that Robson group 1 (nulliparous women with singleton pregnancy in spontaneous labour), group 5 (multiparous women with at least one previous CS) and group 3 (multiparous women without previous CS, with singleton pregnancy in spontaneous labour) were the major contributors to the overall CS rate. These same groups were the major contributors in the eastern Ethiopia and elsewhere, ${ }^{16} 39-44$ though the order was different. The difference in the order of these groups among the studies may be because of the variation in study populations and overall $\mathrm{CS}$ rate. ${ }^{20}$ The high contribution of emergency CS in nullipara (group 1, nulliparous women with singleton pregnancy in spontaneous labour) in our study may be related to inappropriate indications of CS delivery in this group in our study hospital. More than one-third $(35 \%)$ of CS performed in this group is due to abnormal fetal heartbeat patterns. This was high, indicating the possibility of misdiagnosis of abnormal fetal heartbeat pattern. A more active use of the partogram as a tool for decision-making would help clinicians and midwives decide more consistently, instead of relying on too heavily healthcare workers' individual assessment in a busy ward.

The most commonly reported indications for CS were fetal compromise, previous CS and obstructed labour; similar indications have been reported from eastern Ethiopia $^{16}$ and elsewhere in Africa, Asia and Australia. ${ }^{42} 44-47$

In conclusion, this study has shown a high overall CS rate at Hawassa University Referral Hospital. Nulliparous women with singleton pregnancy in spontaneous labour (group 1), multiparous women with at least one previous CS (group 5) and multiparous women without previous CS, with singleton pregnancy, in spontaneous labour (group 3) were the major contributors to the overall high CS rates. Fetal compromise, previous CS and obstructed labour were the major indications for performing CS. There was a high CS rate in low-risk groups (groups 1 and 3). We recommend that all labouring women be regularly followed with partogram, and that they be given the opportunity for instrumental delivery to decrease the use of primary CS among low-risk groups. Fetal heartbeatmonitoring system should be improved to reduce unnecessary CS that could be done due to misdiagnosis of fetal distress. The implementation of midwife-led care and involvement of a companion during labour and childbirth should also be considered. The reasons for the high CS rate among low-risk groups should be explored and the appropriateness of CS should be evaluated to reduce the overall CS rate, which benefits the health system, in general.

Acknowledgements We would like to thank Hawassa University Referral Hospital management and the head of its obstetrics ward for creating a conducive environment in order to accomplish this research. We want to extend our thanks to NORHED-SENUPH project for financial support.

Contributors AAA and BL conceived the study and analysed the data. AAA wrote the proposal and the first draft of the manuscript. SGH, AGT and BL supervised and provided mentorship. All authors contributed to the writing, reviewed the article and approved the final version of the manuscript.

Funding Financial support was obtained from NORHED through the SENUPH (Southern Ethiopia Network of University in Public Health) project (ETH-13/0025).

Competing interests None declared.

Patient consent for publication Not required.

Ethics approval This study was approved by Hawassa University College of Medicine and Health Sciences Institutional Review Board (ref.no.IRB/007/10), and Regional Ethical Committee (Rek Vest) (ref.no.2018/595) in Norway.

Provenance and peer review Not commissioned; externally peer reviewed.

Data availability statement Data are available upon reasonable request.

Supplemental material This content has been supplied by the author(s). It has not been vetted by BMJ Publishing Group Limited (BMJ) and may not have been peer-reviewed. Any opinions or recommendations discussed are solely those of the author(s) and are not endorsed by BMJ. BMJ disclaims all liability and responsibility arising from any reliance placed on the content. Where the content includes any translated material, BMJ does not warrant the accuracy and reliability of the translations (including but not limited to local regulations, clinical guidelines, terminology, drug names and drug dosages), and is not responsible for any error and/or omissions arising from translation and adaptation or otherwise.

Open access This is an open access article distributed in accordance with the Creative Commons Attribution Non Commercial (CC BY-NC 4.0) license, which permits others to distribute, remix, adapt, build upon this work non-commercially, and license their derivative works on different terms, provided the original work is 
properly cited, appropriate credit is given, any changes made indicated, and the use is non-commercial. See: http://creativecommons.org/licenses/by-nc/4.0/.

ORCID iDs

Abdella Amano Abdo http://orcid.org/0000-0001-8538-8291

Bernt Lindtjørn http://orcid.org/0000-0002-6267-6984

\section{REFERENCES}

1 Biccard BM, Madiba TE, Kluyts H-L, et al. Perioperative patient outcomes in the African surgical outcomes study: a 7-day prospective observational cohort study. Lancet 2018;391:1589-98.

2 World Health Organization Human Reproduction Programme. WHO statement on caesarean section rates. Reprod Health Matters 2015;23:149-50.

3 WHO. Appropriate technology for birth. Lancet 1985;2:436-7.

4 Betran AP, Torloni MR, Zhang J, et al. What is the optimal rate of caesarean section at population level? A systematic review of ecologic studies. Reprod Health 2015;12:57.

5 Federal Ministry of Health. Implementationmanual for health care financing reports. Ethiopia: Addis Ababa, 2010.

6 Witter S, Boukhalfa C, Cresswell JA, et al. Cost and impact of policies to remove and reduce fees for obstetric care in Benin, Burkina Faso, Mali and Morocco. Int J Equity Health 2016;15:123.

7 Souza JP, Gülmezoglu A, Lumbiganon P, et al. Caesarean section without medical indications is associated with an increased risk of adverse short-term maternal outcomes: the 2004-2008 who global survey on maternal and perinatal health. BMC Med 2010;8:71.

8 Villar J, Carroli G, Zavaleta N, et al. Maternal and neonatal individual risks and benefits associated with caesarean delivery: multicentre prospective study. BMJ 2007;335:1025.

9 Zhang Y, Zhou J, Ma Y, et al. Mode of delivery and preterm birth in subsequent births: a systematic review and meta-analysis. PLoS One 2019;14:e0213784.

10 Kok N, Ruiter L, Hof M, et al. Risk of maternal and neonatal complications in subsequent pregnancy after planned caesarean section in a first birth, compared with emergency caesarean section: a nationwide comparative cohort study. BJOG 2014;121:216-23.

11 Huang $\mathrm{X}$, Lei J, Tan $\mathrm{H}$, et al. Cesarean delivery for first pregnancy and neonatal morbidity and mortality in second pregnancy. Eur $\mathrm{J}$ Obstet Gynecol Reprod Biol 2011;158:204-8.

12 Betrán AP, Ye J, Moller A-B, et al. The increasing trend in caesarean section rates: global, regional and national estimates: 1990-2014. PLoS One 2016;11:e0148343.

13 Boerma T, Ronsmans C, Melesse DY, et al. Global epidemiology of use of and disparities in caesarean sections. Lancet 2018;392:1341-8.

14 Ethiopia Demographic and Health Survey: CSA and ICF. Ethiopia demographic and health survey 2016. Ethiopia, and Rockville, Maryland, USA: Addis Ababa, 2016.

15 Fesseha N, Getachew A, Hiluf M, et al. A national review of cesarean delivery in Ethiopia. Int J Gynaecol Obstet 2011;115:106-11.

16 Tura AK, Pijpers O, de Man M, et al. Analysis of caesarean sections using Robson 10-group classification system in a university hospital in eastern Ethiopia: a cross-sectional study. BMJ Open 2018;8:e020520.

17 Torloni MR, Betran AP, Souza JP, et al. Classifications for cesarean section: a systematic review. PLoS One 2011;6:e14566.

18 Betrán AP, Vindevoghel N, Souza JP, et al. A systematic review of the Robson classification for caesarean section: what works, doesn't work and how to improve it. PLoS One 2014;9:e97769.

19 Robson M. The Ten Group Classification System (TGCS) - a common starting point for more detailed analysis. BJOG 2015;122:701.

20 WHO. Robson classification: implementation manual. Geneva: World Health Organization, 2017

21 Ethiopian Public Health Institute (EPHI) [Ethiopia] and ICF. Ethiopia mini demographic and health survey 2019: key indicators. Rockville, Maryland, USA: EPHI and ICF, 2019.

22 Federal Ministry of Health. National health workforce update. Human resource development Directorate Bulletin. 2nd edn. Addis Ababa: Ethiopia, 2019.

23 Bergsjø P, Mlay J, Oneko O, et al. Instructions manual for registration of deliveries at the KCMC birth registry, revised edition: department of obstetrics and gynecology KCMC Moshi, Tanzania and. Norway: Department of Public Health and Primary Health Care University of Bergen Bergen, 2010.
24 Stanton C, Ronsmans C, Baltimore Group on Cesarean. Recommendations for routine reporting on indications for cesarean delivery in developing countries. Birth 2008;35:204-11.

25 Senanayake H, Piccoli M, Valente EP, et al. Implementation of the who manual for Robson classification: an example from Sri Lanka using a local database for developing quality improvement recommendations. BMJ Open 2019:9:e027317.

26 Souza JP, Betran AP, Dumont A, et al. A global reference for caesarean section rates (C-Model): a multicountry cross-sectional study. BJOG 2016;123:427-36.

27 Bartuseviciene E, Kacerauskiene J, Bartusevicius A, et al. Comparison of midwife-led and obstetrician-led care in Lithuania: a retrospective cohort study. Midwifery 2018;65:67-71.

28 Jiang X-M, Chen Q-Y, Guo S-B, et al. Effect of midwife-led care on birth outcomes of primiparas. Int J Nurs Pract 2018;24:e12686.

29 McLachlan HL, Forster DA, Davey MA, et al. Effects of continuity of care by a primary midwife (caseload midwifery) on caesarean section rates in women of low obstetric risk: the Cosmos randomised controlled trial. BJOG 2012;119:1483-92.

30 Sandall J, Devane D, Soltani $\mathrm{H}$, et al. Improving quality and safety in maternity care: the contribution of midwife-led care. J Midwifery Womens Health 2010;55:255-61.

31 Tracy SK, Hartz DL, Tracy MB, et al. Caseload midwifery care versus standard maternity care for women of any risk: M@NGO, a randomised controlled trial. Lancet 2013;382:1723-32.

32 Bohren MA, Hofmeyr GJ, Sakala C, et al. Continuous support for women during childbirth. Cochrane Database Syst Rev 2017;7:CD003766.

33 Hodnett ED, Gates S, Hofmeyr GJ, et al. Continuous support for women during childbirth. Cochrane Database Syst Rev 2012;10:CD003766.

34 Kadour-Peero E, Miller N, Vitner D, et al. Who may accompany the parturient to the delivery room? Arch Gynecol Obstet 2019;300:293-7.

35 Sørbye IK, Vangen S, Oneko O, et al. Caesarean section among referred and self-referred birthing women: a cohort study from a tertiary Hospital, northeastern Tanzania. BMC Pregnancy Childbirth 2011;11:55.

36 Amjad A, Amjad U, Zakar R, et al. Factors associated with caesarean deliveries among child-bearing women in Pakistan: secondary analysis of data from the demographic and health survey, 2012-13. BMC Pregnancy Childbirth 2018;18:113.

37 Azene AG, Aragaw AM, Birlie MG. Multilevel modelling of factors associated with caesarean section in Ethiopia: community based cross sectional study. BMC Res Notes 2019;12:724.

38 de Loenzien M, Schantz C, Luu BN, et al. Magnitude and correlates of caesarean section in urban and rural areas: a multivariate study in Vietnam. PLoS One 2019;14:e0213129.

39 Abdel-Aleem H, Shaaban OM, Hassanin Al, et al. Analysis of cesarean delivery at Assiut university hospital using the ten group classification system. Int J Gynaecol Obstet 2013;123:119-23.

40 Costa ML, Cecatti JG, Souza JP, et al. Using a caesarean section classification system based on characteristics of the population as a way of monitoring obstetric practice. Reprod Health 2010;7:13.

41 Litorp H, Kidanto HL, Nystrom L, et al. Increasing caesarean section rates among low-risk groups: a panel study classifying deliveries according to Robson at a university hospital in Tanzania. BMC Pregnancy Childbirth 2013;13:107.

42 Tapia V, Betran AP, Gonzales GF. Caesarean section in Peru: analysis of trends using the Robson classification system. PLoS One 2016;11:e0148138.

43 Yadav RG, Maitra N. Examining cesarean delivery rates using the Robson's ten-group classification. J Obstet 2016;66:1-6.

44 Tognon F, Borghero A, Putoto G, et al. Analysis of caesarean section and neonatal outcome using the Robson classification in a rural district hospital in Tanzania: an observational retrospective study. BMJ Open 2019;9:e033348.

45 Begum T, Nababan H, Rahman A, et al. Monitoring caesarean births using the Robson ten group classification system: a cross-sectional survey of private for-profit facilities in urban Bangladesh. PLoS One 2019;14:e0220693.

46 Makhanya V, Govender L, Moodley J. Utility of the Robson ten group classification system to determine appropriateness of caesarean section at a rural regional hospital in KwaZulu-Natal, South Africa. S Afr Med J 2015;105:292-5.

47 Tanaka K, Mahomed K. The ten-group Robson classification: a single centre approach identifying strategies to optimise caesarean section rates. Obstet Gynecol Int 2017;2017:5648938 